\title{
CORRESPONDENCE.
}

\section{MR. GRAY'S METHODS OF CONSTRUCTING LIFE TABLES.}

\section{To the Editor of the Journal of the Institute of Actuaries.}

Sir,-In Professor Pell's Note on the Construction of Commu. tation Tables (Journal, vol. xxi, page 275), the following passage occurs :-

"I have carefully considered the methods adopted by Mr. Peter Gray in forming the Institute of Actuaries' Tables; and although the formulas made use of are ingenious, and their use may be attended with some advantages, I eannot think that there can be anything in them to counterbalance the comparative ease and simplicity of the method which consists in the direct application of the formulas which express the values of the quantities to be found."

Mr. Gray, in the preface to his remarkable work, Tables and Formula for the Computation of Life Contingencies, says that it "claims to afford greater facilities for the formation of tables of life contingencies than have hitherto been at the command of the computer."

This claim, I believe, was, and still is, a just one. Passing over much that is both ingenions and original, I confine myself to life annuities.

For the computation of these, $\mathbf{M r}$. Gray did not offer a new formula. He took Simpson's (or De Moivre's) famous formula, and gave the means of using it with advantage. What had been laborious, was made easy ; and so far from being indireet, the process is perhaps the most direct that ean be devised.

Then, as to the commutation system, Mr. Gray, still following the principle of "deducing each value from that of the next older life" (these are Simpson's words), gives the most fertile method that has ever come under my notice. He shows (Prob. xxii) how to obtain by a single operation, from the logarithms of $\mathrm{D}_{x}$, those of $\mathrm{N}_{x}, a_{x}$, and $1+a_{x},-$ no other quantities appearing in the process.

I have had more than common experience in annuity calculations, and $I$ have tried many ways; but I know of none superior, or indeed equal to that first mentioned. Annexed is a specimen that will bear comparison with Professor Pell's results, this being of the two the more correct.

Gray's book will surely continue to hold its place as a standard work. It should be in the hands of all who desire to excel in the practical computation of money risks depending on life contingencies.

$$
\begin{aligned}
& \text { I am, Sir, } \\
& \text { Yours faithfully, }
\end{aligned}
$$

London, 24 June 1879.

$$
\text { J. C. HANN YNGTON, }
$$


Males, New South Wales, Annuities, 4 per-cent.

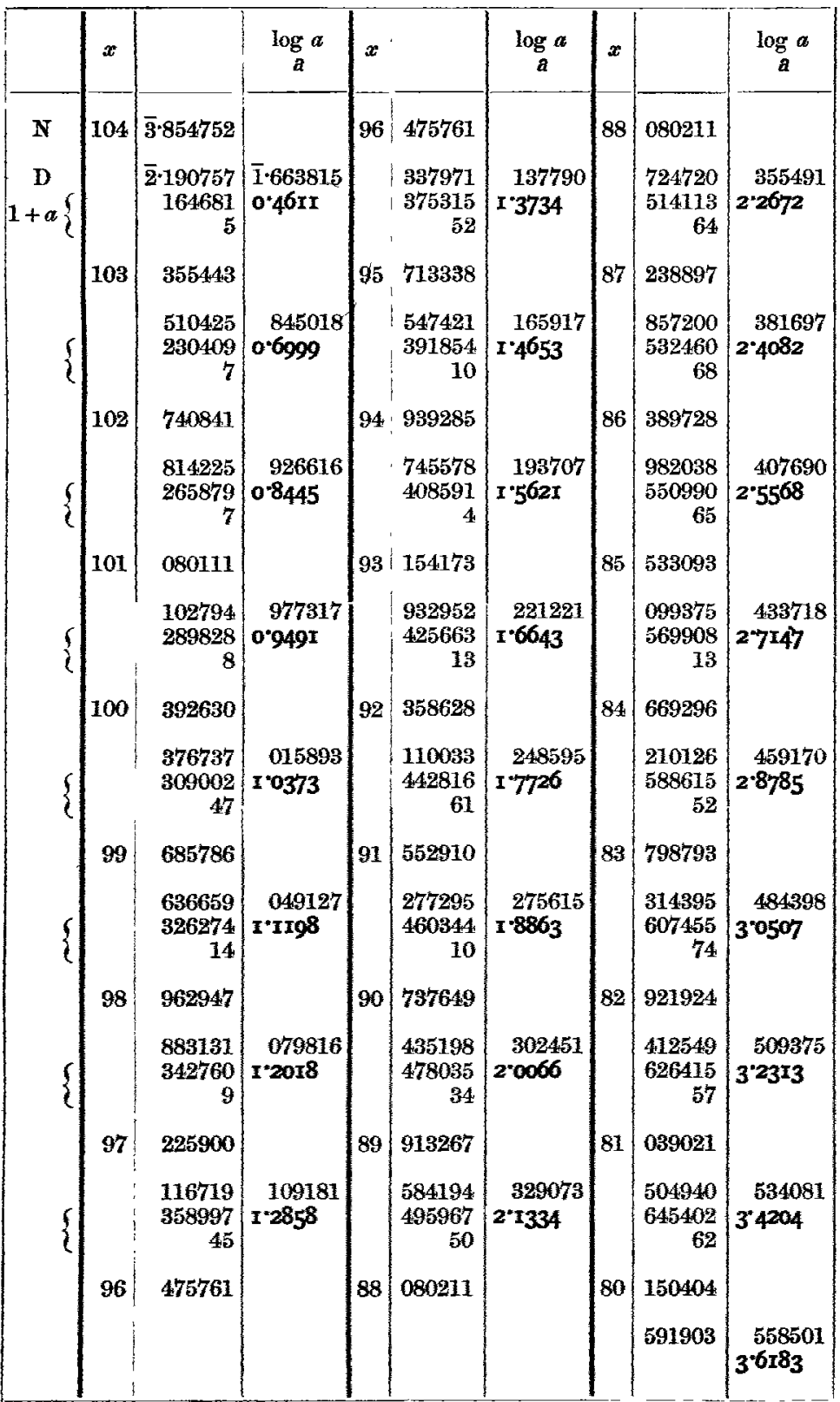

